\title{
Effectiveness of Exercise Therapy on Gait Function in Diabetic Peripheral Neuropathy Patients: A Systematic Review of Randomized Controlled Trials
}

This article was published in the following Dove Press journal:

Diabetes, Metabolic Syndrome and Obesity: Targets and Therapy

\author{
Haimanot Melese iD \\ Abayneh Alamer (D) \\ Melaku Hailu Temesgen (D) \\ Gebresilassie Kahsay \\ Department of Physiotherapy, School of \\ Medicine, College of Health Sciences and \\ Ayder Comprehensive Specialized \\ Hospital, Mekelle University, Mekelle, \\ Ethiopia
}

\begin{abstract}
The purpose of this study was to review the current evidence on the effectiveness of exercise therapy on gait function in patients with diabetic peripheral neuropathy. A comprehensive search of literature published between October 2010 and May 2020 was conducted using the following electronic databases; PubMed, AMED, CINAHL, ScienceDirect, Cochrane Library, PEDro and Google Scholar. Randomized control trials conducted to determine the effectiveness of exercise therapy on gait function in patients with diabetic neuropathy were included in this review. Non-English language published papers were excluded. This review was done in compliance with the Preferred Reporting Items for Systematic Reviews and Meta-analyses (PRISMA) guidelines. Data extraction and risk of bias assessment of the studies were carried out independently by two authors. The methodological quality of the studies was evaluated using the PEDro scale and GRADE approach. The overall methodological quality of studies rated from moderate to high. Metaanalysis was not carried out due to the heterogeneity of included trials. The primary outcome measures of gait functions were the six-minute walk test, 10-meter walk test and Tinetti scale. Nine randomized controlled trials with 370 participants were analyzed. Out of them, eight studies proved its effectiveness on gait function on individuals with diabetic peripheral neuropathy. The finding of this study suggested that multi-component exercise therapy consisted of strength, ROM exercise, balance, flexibility and stretching exercises, circuit exercise training, and gait training found to enhance gait function for individuals suffering with diabetic peripheral neuropathy compared to control groups.
\end{abstract}

Keywords: exercise therapy, diabetic pain, functional training, gait, peripheral neuropathy, systematic review

\section{Introduction}

Diabetic peripheral neuropathy (DPN) is one of the long-term complications of diabetes caused by peripheral sensory and motor nerve dysfunction due to the disease sequelae. ${ }^{1,2}$ This is the most common chronic complication, which could lead to morbidity and mortality in individuals with diabetes and that contributed a large economic burden for diabetes care. ${ }^{3,4}$ Globally the estimated prevalence of DPN was 15.3-72.3/100,000 person-years. $^{5}$ In developing countries the prevalence of peripheral polyneuropathy in individuals with diabetes was approximately $25-50 \%{ }^{4,6}$
Correspondence: Haimanot Melese

Tel +2510927608383

$\mathrm{Fax}+2510344416681 / 91$

Email haimanotphysio@gmail.com 
DPN is a progressive degeneration of the peripheral nerves, particularly in the lower limbs, ${ }^{7}$ which affects the sensory, motor, and autonomic components of the peripheral nerves, resulting in loss of protective sensation, intrinsic foot muscle dysfunction and anhydrosis of the foot. ${ }^{8}$ DPN induces changes to the sensory and motor control system that affects the quantity and quality of the sensory information that is involved in the generation and control of the gait. ${ }^{9}$ This can lead to reduced mobility and increases fall risk, which is related to reduced range of motion, muscle strength and changes in gait mechanics (gait cycle, decreased walking cadence and gait speed). ${ }^{10-14}$

Nowadays, several rehabilitation approaches were used for the treatment of DPNs. These include pharmacological drugs, manual therapy, electrotherapy modalities, acupuncture, and exercise therapy. ${ }^{15-19}$ However; exercise therapy had great attention on improvement of gait function for individuals suffering with DPN. ${ }^{20-22}$ Therapeutic exercise protocol, including range of motion exercise, muscle strengthening, circuit exercise training, gait and balance training. A prior review done on different exercise therapy had showed enhancements in the gait ability of physically frail older adults. ${ }^{23}$ Moreover, Allet et al, ${ }^{24}$ studied the intervention effect consisted of physiotherapeutic training, including gait and balance exercises with function orientated strengthening program geared to concurrently improving the balance and gait of diabetic patients. In contradiction to this, Sartor et $\mathrm{al}^{25}{ }^{25}$ reported that a combination of stretching, strengthening, and functional foot and ankle exercises (twice a week over 12 weeks) had no significant improvement on foot function in subjects with DPN. Nonetheless, the efficacy of exercise therapy on gait function of individuals suffering with DPNs remains questionable.

Thus, to the extent of the authors' knowledge, there is a paucity of evidence on the effectiveness of exercise therapy on the gait function in patients with DPN in a systematic way. Therefore, the purpose of this review was to systematically summarize the recent randomized controlled trials (RCTs) on the effectiveness of exercise therapy programs on gait function in patients with DPN.

\section{Methods}

\section{Design}

This systematic review was conducted and reported in compliance with the Preferred Reporting Items for Systematic Reviews and Meta-analyses (PRISMA) guidelines. $^{26}$

\section{Searching Strategy}

An electronic database, search by title and abstract was conducted in between October 2010 and May 2020 on the following databases: (1) PubMed, (2) the Cumulative Index to Nursing and Allied Health Literature (CINAHL), (3) The Allied and Complimentary Medicine Database (AMED), (4) Physiotherapy Evidence Database (PEDro), (5) ScienceDirect, (6) Google Scholar and (7) Cochrane Library. Specific search strategies depended on the particular database being searched. For the keywords and database search strategy we used the following: "Diabetic neuropathy"/"peripheral neuropathy" AND "gait function"; "gait therapy"/"gait rehabilitation";/“muscles strengthening exercises"/"exercise therapy"/"range of motion exercises"/“balance training"/"gait training"/ "Circuit training"/"sensor-based interactive exercise training" AND "RCTs". Hand searches of the reference list of included articles were also performed.

\section{Eligibility Criteria}

RCTs conducted to determine the effectiveness of exercise therapy on gait function in patients with DPN were included in this review. Only full-text articles published in English were included. Observational studies, quasiexperimental studies and conference abstracts were excluded from this review. Adult diabetic mellitus (DM) patients with peripheral neuropathy were considered. RCTs comparing the effectiveness of exercise therapy with the conventional therapy and/usual medical care/no intervention were included. Exercise therapy is defined as all rehabilitative exercise programs given to the DPN patients, which included at least one and or combination of two or more exercises of the following: muscle strengthening training, circuit exercise training, range of motion exercise, balance training exercise, flexibility and stretching exercises, gait exercise training, and sensorbased interactive exercise training.

\section{Study Selection}

One reviewer (HM) conducted the electronic database searches and screened the title and abstracts. Full texts of potential eligible articles were retrieved and independently screened by two reviewers (HM and AA). Disagreements were resolved by consensus without the need for a third reviewer (MH), who was available. Initial disagreements were due to intervention criteria, ${ }^{27}$ study population, ${ }^{28}$ study design. ${ }^{29,30}$ 


\section{Risk of Bias in Individual Studies}

The methodological quality of each of the included studies was evaluated using the PEDro scale, ${ }^{31,32}$ and graded by two independent reviewers (HM and $\mathrm{AA}$ ). The disagreement between the two authors was settled by consensus. PEDro scale is the most commonly used tools for quantifying the methodological quality of RCTs in physiotherapy. ${ }^{33,34}$ It consists of a checklist of 10 scored yes-or-no questions pertaining to the methodological quality of RCTs. ${ }^{32}$ It includes eligibility criteria, random allocation, concealed allocation, outcome measurement, similarity at baseline, greater than $85 \%$ follow-up for at least one outcome measure, intention-to-treat analysis, between-group statistical comparison and blinding (subject, assessor, and therapist). The overall quality of the evidence and the strength of recommendations were also evaluated using the GRADE approach. ${ }^{35}$ The GRADE approach specifies four quality levels (high, moderate, low, and very low). The overall evidence was downgraded depending on the presence of five factors: limitations (due to risk of bias); consistency of results; directness (eg, whether participants are similar to those about whom conclusions are drawn); precision (ie, sufficient data to produce narrow confidence intervals); and other (eg, publication bias). (Table 1)

\section{Data Extraction}

The data extraction sheet has been developed based on the data retrieval template of the Cochrane Consumer and Communication Review Group. Two reviewers (HM and AA) extracted the data independently and the third author $(\mathrm{MH})$ checked the extracted data. Disagreements were resolved by discussion between the review authors. The data were extracted from each RCT by using the following items: authors name and year of publication, diabetic neuropathy definition (Questionnaire of the Michigan Neuropathy Screening Instrument score, ability to walk, type of DM and duration), number of participants in both experimental and control groups, types of interventions in both experimental and control groups, mean follow-up time, mean age of the participants, treatment outcomes (baseline, follow-up and end of treatment), primary outcome measures, study design, study results, and conclusions.

\section{Results}

\section{Study Selection}

A search strategy of an electronic database found a total of 5882 articles. After adjusting for the duplicates, 2099 have remained. After the title and abstract screening among 803 studies, 758 studies were excluded. After full text screening out of 45 articles, 9 RCTs were included in this review (Figure 1).

\section{Characteristics of the Included Studies}

The detailed summary of the included trials is presented in Table 2. All selected studies were RCTs published in English. These studies have been published in Switzerland, ${ }^{21}$ Netherlands, ${ }^{36}$ Brazil $^{25}$ Japan, ${ }^{22}$ Italy, ${ }^{37}$ USA, ${ }^{38,39}$ and Egypt $^{40,41}$ between 2010 and 2019.

Nine RCTs with a total of 370 participants were analyzed. The mean age of participants in the experimental groups ranged from $65.2(12.8)^{38}$ to $73(10)^{37}$ and from 59 $(11)^{22}$ to $65.5(13)^{36}$ in the control groups. The minimum duration of DM since diagnosed was $2.4^{22}$ and the maximum 27.2 years. ${ }^{39}$ The primary outcomes were the sixminute walk test, 10-meter walking test, and Tinetti scale walk. The sample size of the participants in the included studies ranged from 27-71 individuals, in both the experimental and control groups..$^{21,37}$ The duration of the intervention ranged from 30-60 minutes for each session,,$^{20,21,25,40} 2-5$ times per week, ${ }^{21,25,37} 2$ to 24 weeks for both experimental and control groups. ${ }^{22,36}$

\section{Risk of Bias of Included Studies}

The risk of bias and methodological quality of the included studies are described in the Table 1 . Randomization, baseline similarity, intention to treat analysis, between group comparison and point measures were assessed in all of the included studies. However, not all studies have reported on concealment allocations, blinding of therapists and patients. Four of the included trials have blinded the assessor. ${ }^{25,37,38,41}$ The PEDro score of the included studies ranged from six to eight, with a mean score of seven that suggested the overall quality of studies. Based on the quality of the evidence and the strength of the recommendations, GRADE approach and PEDro score, the overall quality of the trails were ranged from moderate to high. (Table 1)

\section{Interventions}

The studies compared the effectiveness of exercise therapy and comparison/control group: pharmacological treatment and/self-care instructions and/neither treatment, nor specific advices were reviewed. 
Table I Methodological Quality of Included RCTs

\begin{tabular}{|c|c|c|c|c|c|c|c|c|c|}
\hline $\begin{array}{l}\text { PEDro Scale } \\
\text { Items }\end{array}$ & $\begin{array}{l}\text { Allet } \\
\text { et al, } \\
2010^{21}\end{array}$ & $\begin{array}{l}\text { Refay } \\
\text { et al, } \\
2013^{20}\end{array}$ & $\begin{array}{l}\text { Mueller } \\
\text { et al, } \\
2013^{38}\end{array}$ & $\begin{array}{l}\text { Sartor } \\
\text { et al, } \\
2014^{25}\end{array}$ & $\begin{array}{l}\text { Taveggia } \\
\text { et al, } \\
2014^{37}\end{array}$ & $\begin{array}{l}\text { Melai } \\
\text { et al, } \\
2014^{36}\end{array}$ & $\begin{array}{l}\text { Grewal } \\
\text { et al, } \\
2015^{39}\end{array}$ & $\begin{array}{l}\text { Suzuki } \\
\text { et al, } \\
2019^{22}\end{array}$ & $\begin{array}{l}\text { Saleh et } \\
\text { al } 2019^{40}\end{array}$ \\
\hline Eligibility & Yes & Yes & Yes & Yes & No & Yes & Yes & Yes & Yes \\
\hline $\begin{array}{l}\text { Random } \\
\text { allocation }\end{array}$ & Yes & Yes & Yes & Yes & Yes & Yes & Yes & Yes & Yes \\
\hline $\begin{array}{l}\text { Concealed } \\
\text { allocation }\end{array}$ & No & Yes & Yes & Yes & No & Yes & Yes & No & Yes \\
\hline $\begin{array}{l}\text { Baseline } \\
\text { comparability }\end{array}$ & Yes & Yes & Yes & Yes & Yes & Yes & Yes & Yes & Yes \\
\hline $\begin{array}{l}\text { Blind } \\
\text { participants }\end{array}$ & No & No & No & No & No & No & No & No & No \\
\hline $\begin{array}{l}\text { Blinded } \\
\text { therapist }\end{array}$ & No & No & No & No & No & No & No & No & No \\
\hline $\begin{array}{l}\text { Blinded } \\
\text { assessor }\end{array}$ & No & No & Yes & Yes & Yes & No & No & No & Yes \\
\hline $\begin{array}{l}\text { Adequate } \\
\text { followup }\end{array}$ & Yes & Yes & Yes & Yes & Yes & Yes & Yes & Yes & Yes \\
\hline $\begin{array}{l}\text { Intention to } \\
\text { treat analysis }\end{array}$ & Yes & Yes & Yes & Yes & Yes & Yes & Yes & Yes & Yes \\
\hline $\begin{array}{l}\text { Between } \\
\text { group } \\
\text { comparison }\end{array}$ & Yes & Yes & Yes & Yes & Yes & Yes & Yes & Yes & Yes \\
\hline $\begin{array}{l}\text { Point } \\
\text { estimates }\end{array}$ & Yes & Yes & Yes & Yes & Yes & Yes & Yes & Yes & Yes \\
\hline $\begin{array}{l}\text { Total score of } \\
\text { quality }\end{array}$ & $6 / 10$ & $7 / 10$ & $8 / 10$ & $8 / 10$ & $7 / 10$ & $7 / 10$ & $7 / 10$ & $6 / 10$ & $7 / 10$ \\
\hline $\begin{array}{l}\text { Graded } \\
\text { approach }\end{array}$ & Moderate & Moderate & High & High & Moderate & Moderate & Moderate & Moderate & Moderate \\
\hline
\end{tabular}

\section{Outcome Measures}

Among the included trials four studies ${ }^{20,25,36,40}$ measured gait function by using gait velocity and four studies ${ }^{20-22,40}$ used cadence. Two studies ${ }^{37,38}$ used ROM, 10-meter walking test and Tinetti scale to measure physical function and walking endurance. Only one study measured the gait function by using time spent in sitting, standing and walking (Appendix). ${ }^{39}$

\section{Effects of Exercise Therapy on the Gait Function}

Data extracted from the papers are summarized and presented in Table 2. Overall, all nine studies with 370 participants of DPN had investigated the effect of exercise therapy compared to control groups (no interventions/ pharmacological treatment/usual self-care on gait function. ${ }^{20-22,25,36-40}$ Out of the included studies, eight of them $(n=315)$ had confirmed that exercise therapy is effective on gait function for individuals suffering with DPN compared to the control groups. ${ }^{20-22,36-40}$ But one study $(n=55)$ reported that a combination of stretching, strengthening, and functional range of motion exercises (twice a week over 12 weeks) had no significant improvement on foot function in subjects with DPN. ${ }^{25}$

A total of seven studies $(\mathrm{n}=311)$ assessed gait function using gait assessment parameters (velocity $(\mathrm{m} / \mathrm{s})$, stride 


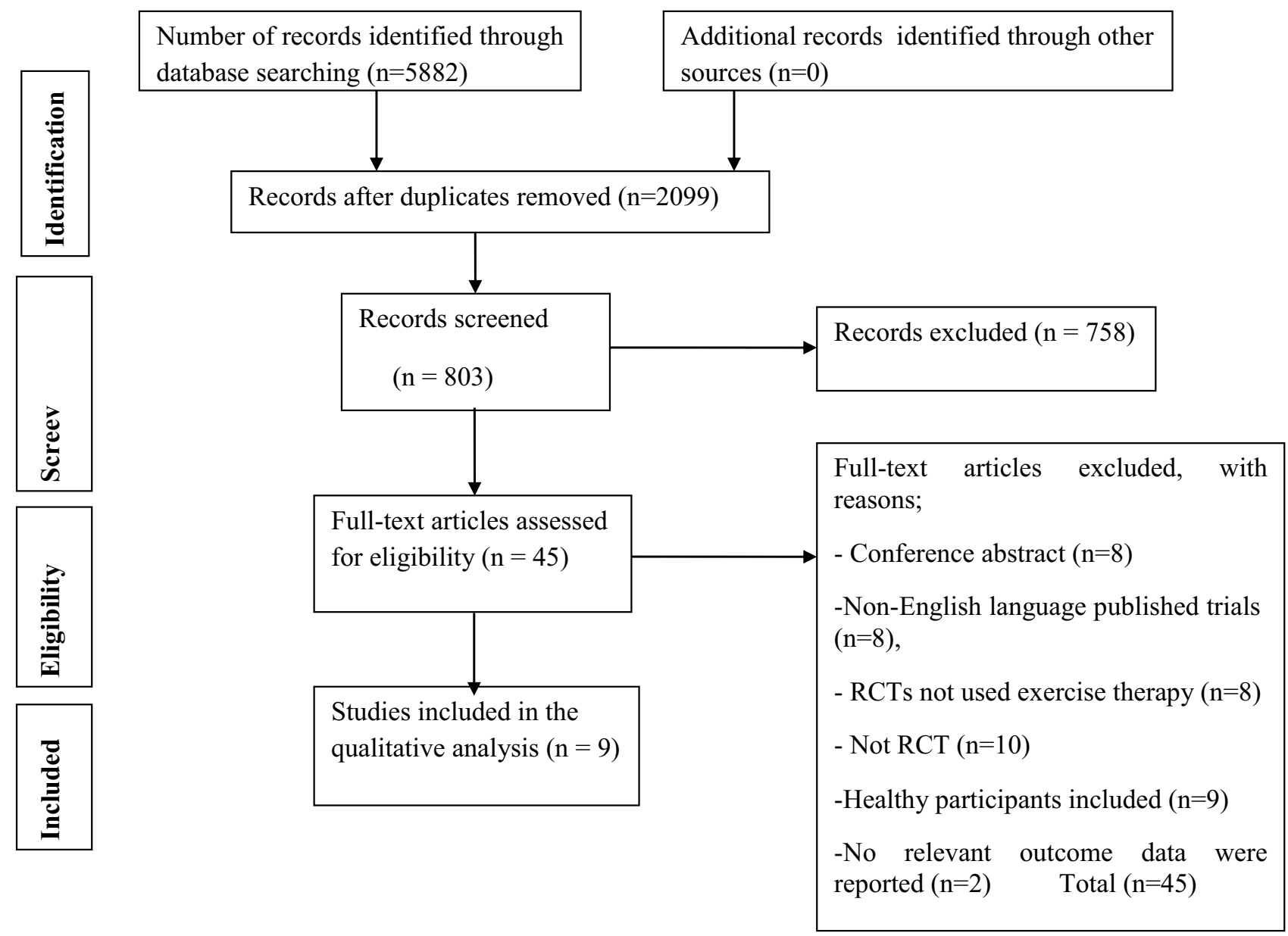

Figure I Preferred Reporting Items for Systematic Reviews and Meta-analyses (PRISMA) diagram.

length, step length, cadence (steps/min), step time (s), time-to-peak pressure (PP) and double support time (s), ${ }^{20-22,25,36,39,40}$ and other two studies measured using the six-minute walk test, 10-meter walking test and theTinetti scale walk. ${ }^{37,38}$

\section{Discussion}

This systematic review evaluated the current evidence on the effectiveness of exercise therapy on gait function in patients with DPN. To the extent of the authors' knowledge, a systematic review of RCTs about exercise therapy in patients with DPN has not been performed yet. Therefore, the purpose of this review was to synthesize the effectiveness of exercise therapy on gait function in patients with DPN. The findings of this review demonstrated that exercise therapy had a beneficial effect in patients with DPN compared to the control groups. Out of nine studies, eight RCTs confirmed the effectiveness of exercise therapy on gait function in patients with diabetic neuropathy with a high methodological quality. The amount of exercise (dose) needed to achieve the desired improvements in gait function has not been determined and may vary from one patient to the next. In the reviewed studies, the time that participants engaged in exercise therapy ranged from 30 minutes to one hour at a time, twice to five times a week, and four weeks to 24 months duration. Due to the heterogeneity of the interventions, the gait functions of the participants were assessed using different outcome measures. All included studies investigated the posttreatment effect of exercise therapy on gait functions. For instance, the Refay et al, ${ }^{20}$ study indicated that combinations of range of motion (ROM) exercises of lower extremity, muscle strengthening exercise for toes flexor/extensor and foot intrinsic muscle, balance training and gait training exercises improved walking speed, cadence and ankle range of motion with significant decrease of step time, while for the control group, no significant difference were noted. This might be due to 


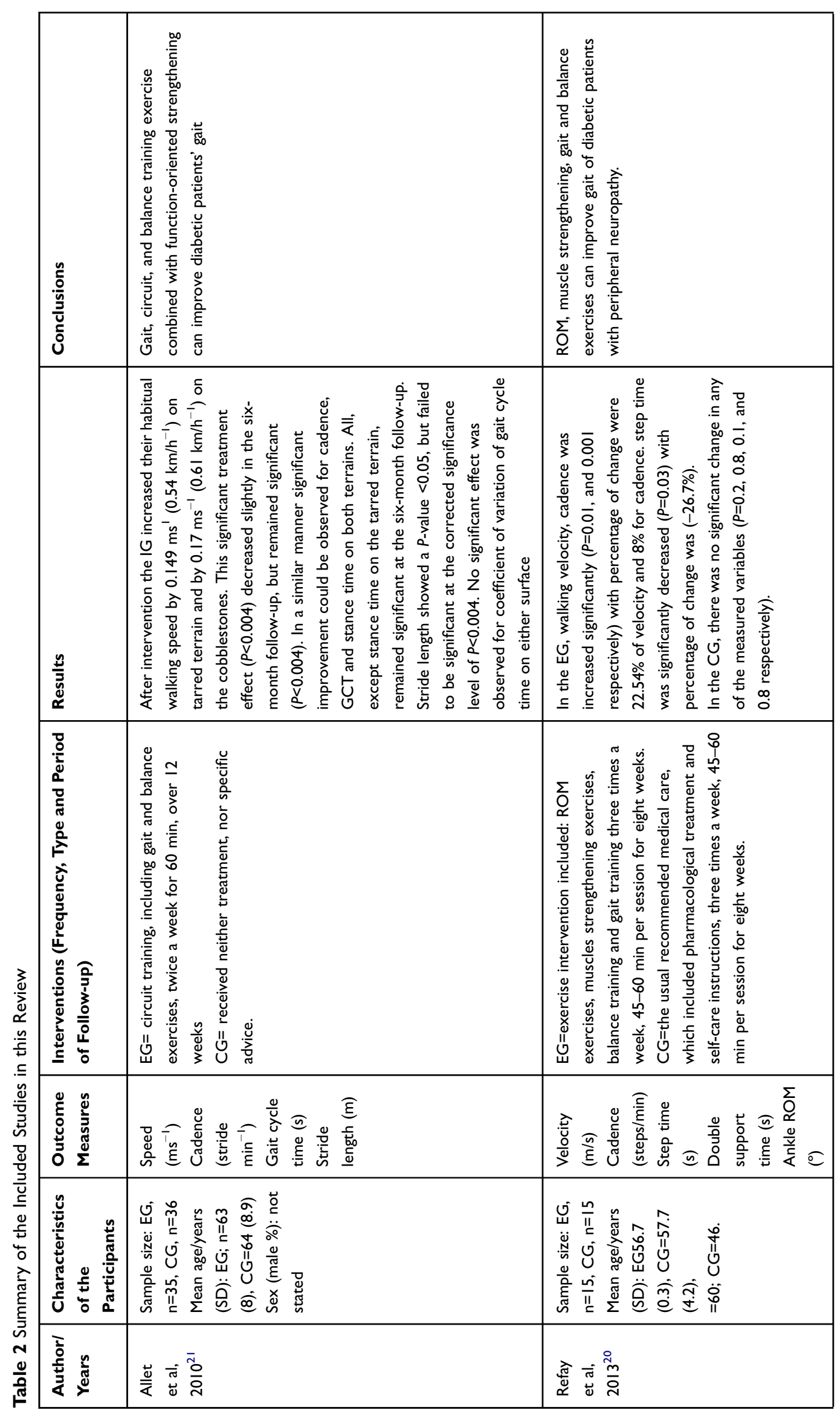




\begin{tabular}{|c|c|c|}
\hline 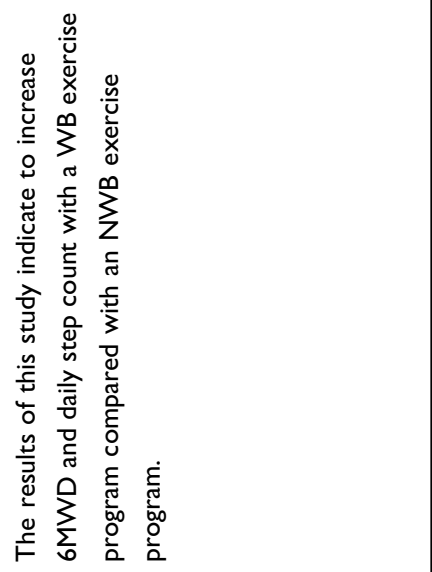 & 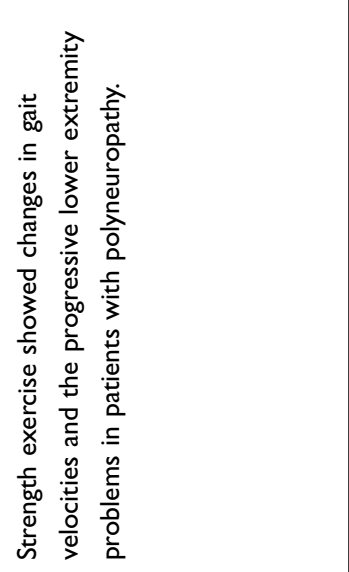 & 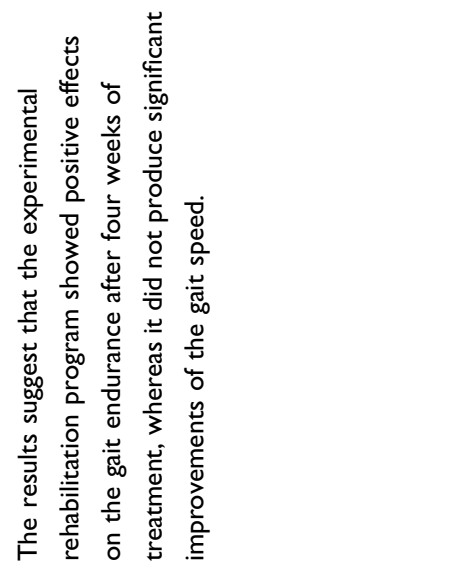 \\
\hline 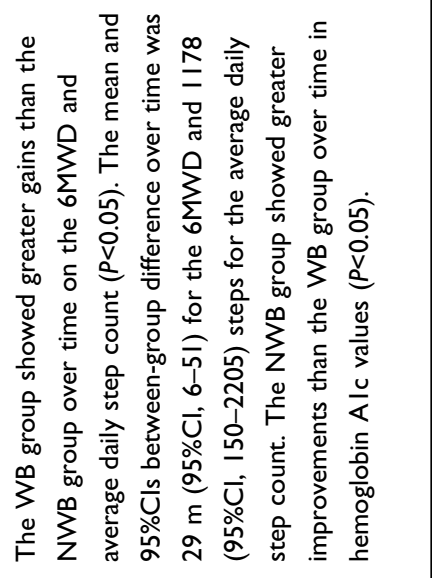 & 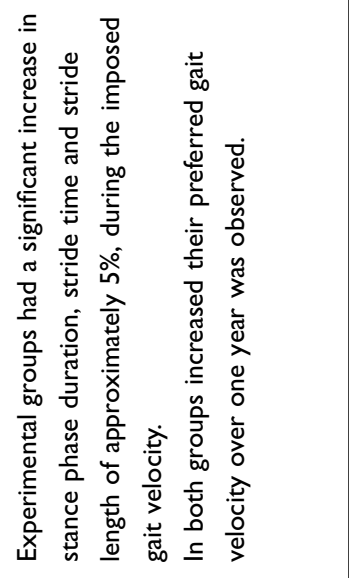 & 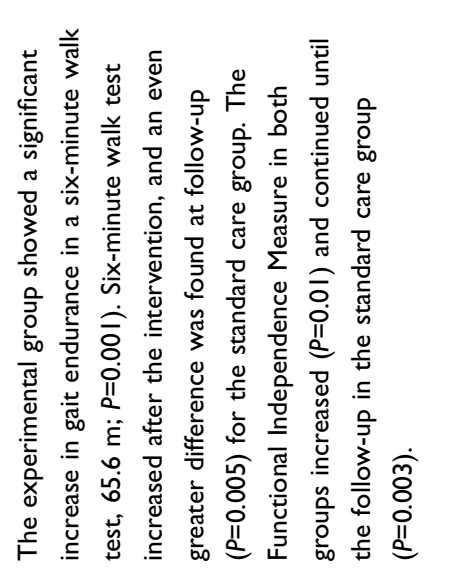 \\
\hline 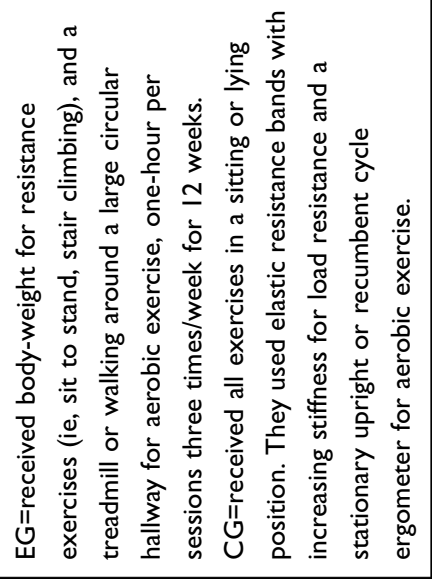 & 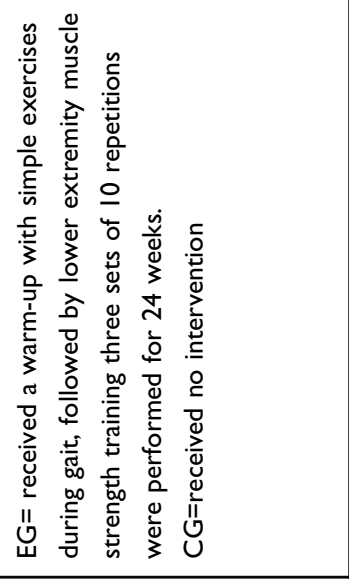 & 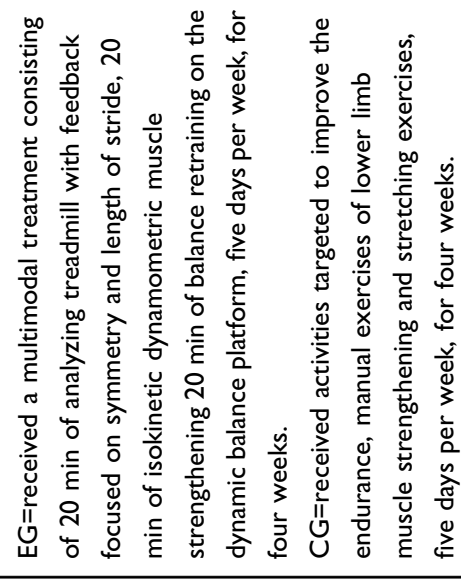 \\
\hline 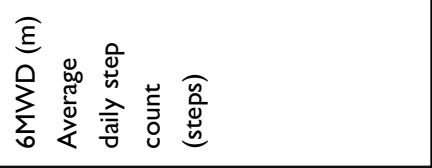 & 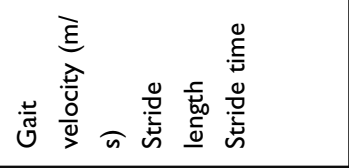 & 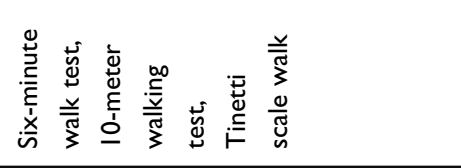 \\
\hline 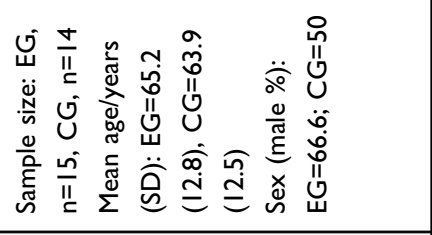 & 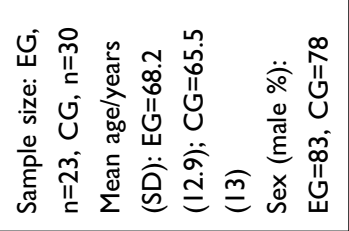 & 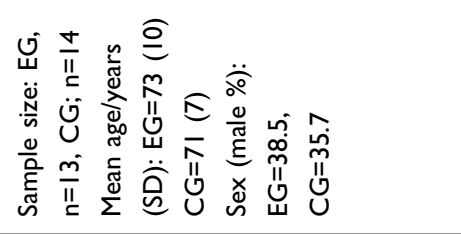 \\
\hline 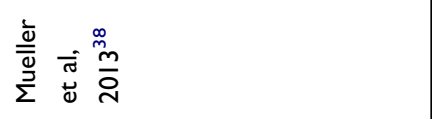 & 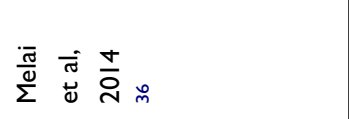 & 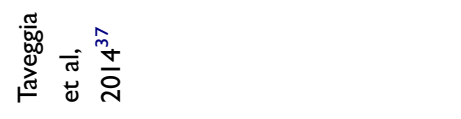 \\
\hline
\end{tabular}




\begin{tabular}{|c|c|c|c|}
\hline & 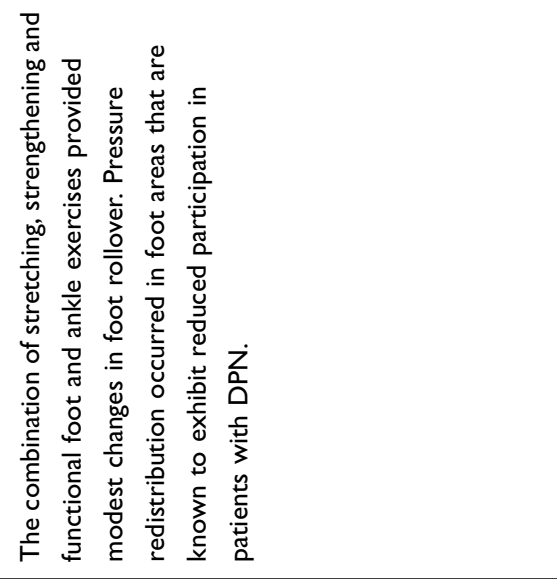 & 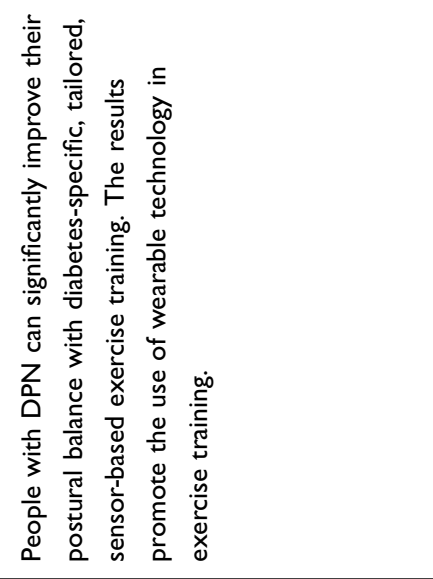 & 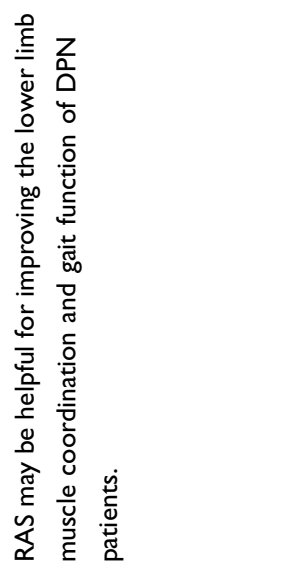 \\
\hline & 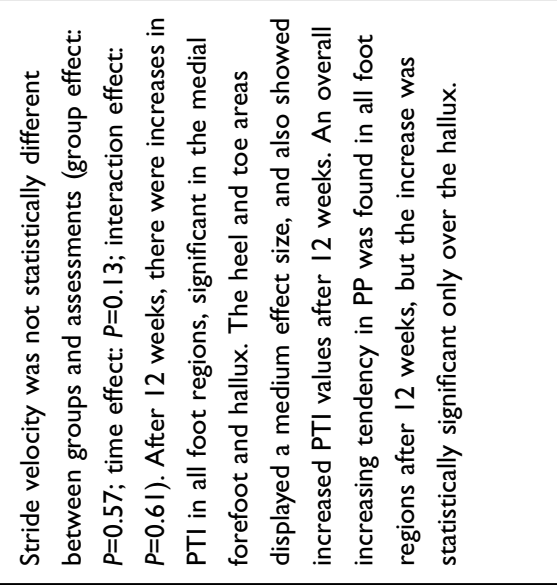 & 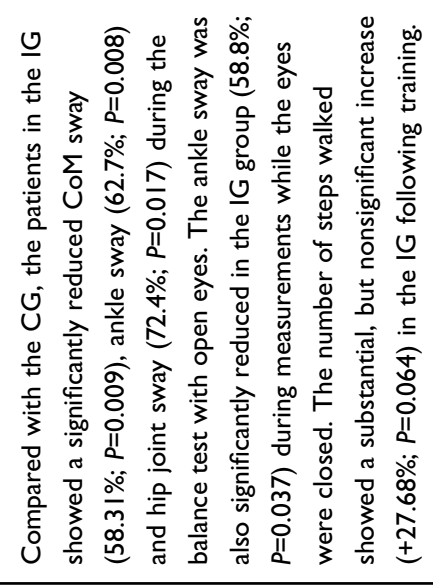 & 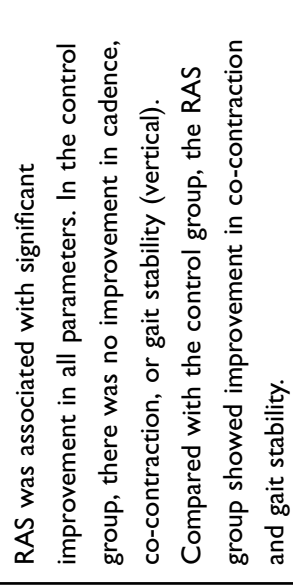 \\
\hline 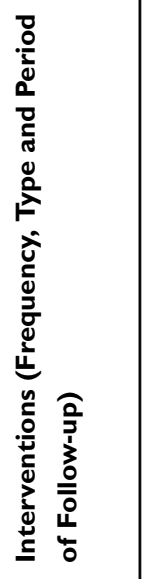 & 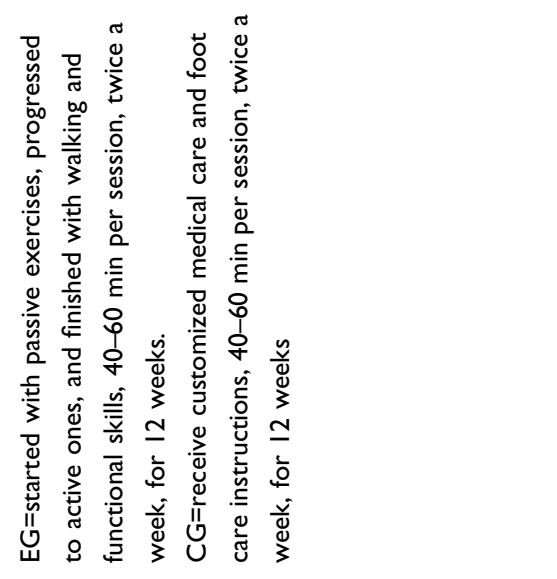 & 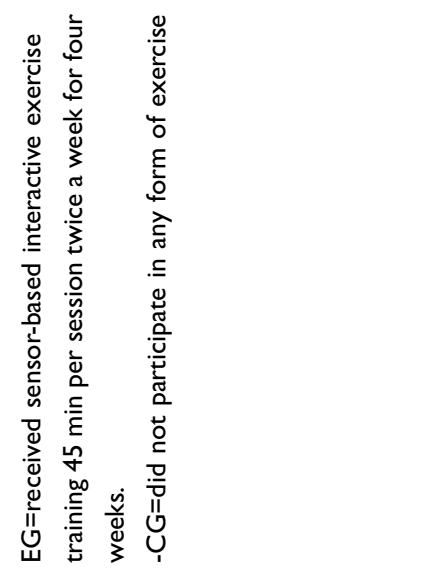 & 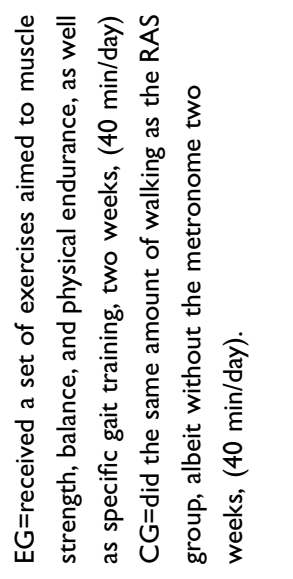 \\
\hline 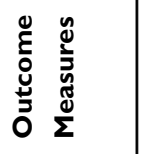 & 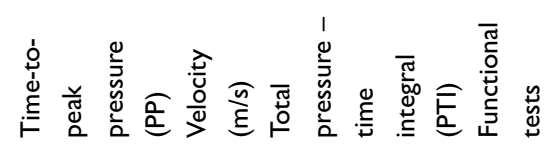 & 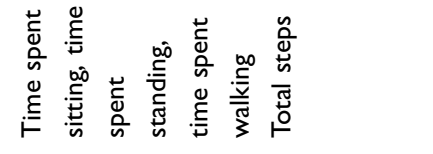 & 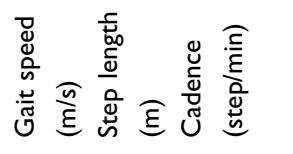 \\
\hline 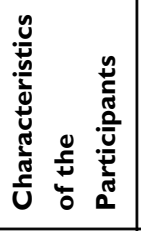 & 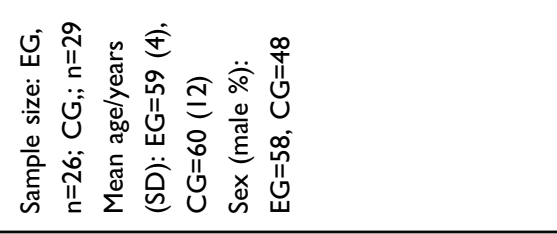 & 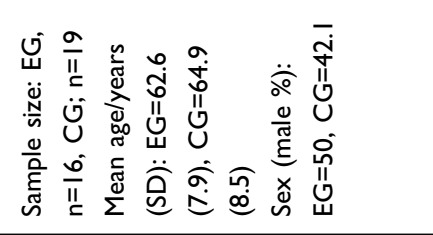 & 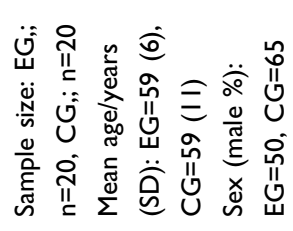 \\
\hline 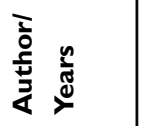 & 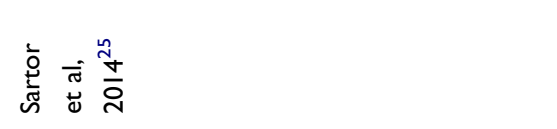 & 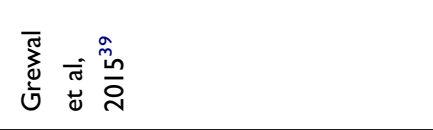 & 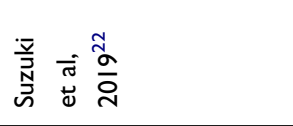 \\
\hline
\end{tabular}




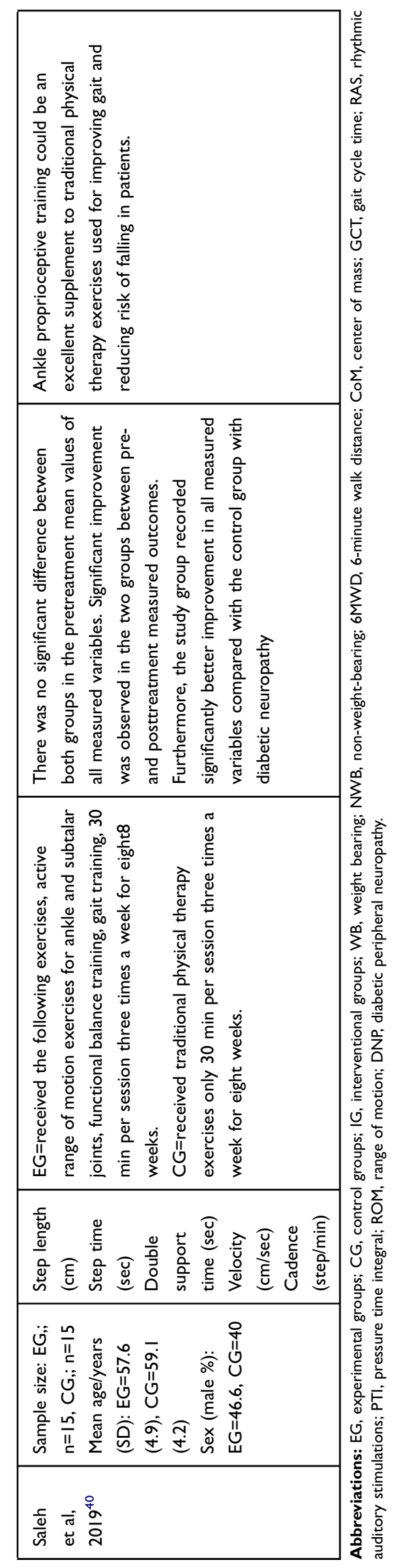

exercise training, be able to improve macro and microvascular factors in diabetes. ${ }^{42,43}$ Therefore, vascular adaptations caused by exercise may facilitate blood flow to peripheral nerves, moreover, it could improve gait function. Similarly, the study by Allet et al, ${ }^{21}$ showed that gait and balance exercises with function-oriented strengthening, improved diabetic patients' gait functions compared with a control group of no treatment. Cadence contributed $80 \%$, whereas stride length only contributed $20 \%$ to the change of gait velocity. This result was also supported by a study by Saleh et al. ${ }^{40}$ This may be due to the treatment or to diabetic patients' potential to regulate their cadence and stride length. Stride length also tended to increase after the intervention, but was not significant at the corrected significance level. Whereas the study by Melai et al, ${ }^{36}$ stated that stride length increases by $5 \%$ approximately in the exercise therapy group. It is supported by Gholami et al, ${ }^{44}$ which found $7 \%$ improvement in HbAlc content following 12-week exercise training. Hence, it may be attributed to improved glucose control as a result of exercise intervention which could benefit gait function of subjects with DPN. $^{45}$

Despite this, the study done by Sartor et $a 1,{ }^{25}$ on the effects combination of strengthening, stretching and functional training on foot function in patients with diabetic neuropathy in intervention group primary outcome peak pressure (PP) reported that there was no statistically significant change under the six foot areas. The intention-to-treat comparisons yielded softening of heel strike (delayed heel time-to-peak pressure (TPP), better eccentric control of forefoot contact (decrease in ankle extensor moment, increase in function of ankle dorsiflexion), earlier lateral forefoot contact with respect to medial forefoot (TPP anticipation), and increased participation of hallux (increased PP) and pressure-time integral (PTI), and toes (increase in PTI, medium effect size). A slower COP mean velocity, and an increase in overall foot and ankle function were also observed, which may result from changes in the pressure variables in the foot.

Taveggia et al, ${ }^{37}$ indicated that a combination of treadmill gait training, muscle strengthening and balance retraining showed a substantially greater improvement in gait endurance after four weeks compared to standard care. However, there was no significant improvement in gait speed.

Mueller et $\mathrm{al}^{38}$ indicated that the weight-bearing exercise showed greater gait function improvement compared to the non-weight-bearing exercise group over time 
(significant interactions) in the primary outcomes of the six-minute walk distance (6MWD) and average daily step count. The mean between-group difference over time was $29 \mathrm{~m}(95 \% \mathrm{CI}, 6-51)$ for the 6MWD and 1178 steps $(95 \%$ CI) for the average daily step count. However, nonweight-bearing exercises showed greater improvements than the weight-bearing group over time (significant interaction) in hemoglobin A1C values. Nevertheless Grewal et $\mathrm{al}^{39}$ stated that the number of steps walked showed a substantial, but nonsignificant increase (27.68\%) in the intervention group following weight-bearing exercise training.

A study done by Suzuki et al, ${ }^{22}$ showed that gait training exercises supported by rhythmic auditory stimulation over the two weeks of treatment improved gait parameters (ie, gait speed, step length, cadence) of DPN patients.

Taken together, most of the included studies highlighted that exercise therapy had significant improvement on gait function among subjects with DPN compared to the control groups.

\section{Limitations of the Study}

This review had the following limitations: this review included only English language published articles. Hence, there might be a chance of missing articles published in non-English languages. Due to the heterogeneity across the included studies, meta-analysis was not carried out.

\section{Clinical Implication}

This review indicates that, exercise therapy improved in gait parameters and physical function of patients with DPN. This systematic review suggests including exercise therapy in the rehabilitation programs, since it is feasible and beneficial for patients with DPN.

\section{Conclusion}

Exercise therapy is found to improve gait function of patients with DPN. Specific exercise training programs, including range of motion, muscle strengthening, circuit training, stretching exercise, gait, and balance exercises can improve gait of diabetic patients with peripheral neuropathy. Clinical decision-making should take into account the type and intensity of exercise and patient's tolerability related to each exercise.

\section{Ethical Approval}

Ethical approval or patient consent was not required, since the present study was a review of previously published literature.

\section{Author Contributions}

All authors' have contributed to the work reported, in the conception, study design, execution, acquisition of data, analysis and interpretation, drafted or written, or substantially revised or critically reviewed the article, agreed on the journal to which the article was submitted, reviewed and agreed on all versions of the article before submission, during revision. Finally, in any significant changes introduced at the proofing stage, the authors agree to take responsibility and be accountable for the contents of the article.

\section{Funding}

There was no provided financial support to conduct this review.

\section{Disclosure}

The authors report no conflicts of interest in this work.

\section{References}

1. Callaghan BC, Cheng HT, Stables CL, et al. Diabetic neuropathy: clinical manifestations and current treatments. Lancet Neurol. 2012;11(6):521-534. doi:10.1016/S1474-4422(12)70065-0

2. Said G. Diabetic neuropathy-a review. Nat Clin Pract Neurol. 2007;3(6):331-340. doi:10.1038/ncpneuro0504

3. Vinik AI, Nevoret M-L, Casellini C, et al. Diabetic neuropathy. Endocrinol Metab Clin. 2013;42(4):747-787. doi:10.1016/j. ec1.2013.06.001

4. Harris M, Eastman R, Cowie C. Symptoms of sensory neuropathy in adults with NIDDM in the US population. Diabetes Care. 1993;16 (11):1446-1452. doi:10.2337/diacare.16.11.1446

5. Van Hecke O, Austin SK, Khan RA, et al. Neuropathic pain in the general population: a systematic review of epidemiological studies. PAIN $^{\circledR}$. 2014;155(4):654-662. doi:10.1016/j.pain.2013.11.013

6. Boulton AJ, Malik RA, Arezzo JC, et al. Diabetic somatic neuropathies. Diabetes Care. 2004;27(6):1458-1486. doi:10.2337/ diacare.27.6.1458

7. Nozabieli AJL, Martinelli AR, de Camargo MR, et al. Diabetic peripheral neuropathy in ankles and feet: muscle strength and plantar pressure. Int J Diabetes Dev Ctries. 2014;34(2):82-88.

8. Shenoy AM. Guidelines in practice: treatment of painful diabetic neuropathy. Continuum. 2012;18(1):192-198.

9. Varraine E, Bonnard M, Pailhous J. Interaction between different sensory cues in the control of human gait. Exp Brain Res. 2002;142 (3):374-384. doi:10.1007/s00221-001-0934-3

10. Fernando M, Crowther R, Lazzarini P, et al. Biomechanical characteristics of peripheral diabetic neuropathy: a systematic review and meta-analysis of findings from the gait cycle, muscle activity and dynamic barefoot plantar pressure. Clin Biomech. 2013;28(8):831845. doi:10.1016/j.clinbiomech.2013.08.004 
11. Andersen H. Motor dysfunction in diabetes. Diabetes Metab Res Rev 2012;28:89-92. doi:10.1002/dmrr.2257

12. Gomes AA, Onodera AN, Otuzi MEI, et al. Electromyography and kinematic changes of gait cycle at different cadences in diabetic neuropathic individuals. Muscle Nerve. 2011;44(2):258-268. doi:10.1002/mus.22051

13. Foss-Freitas MC, Marques WJ, Foss MC. Autonomic neuropathy: a high risk complication for type 1 diabetes mellitus. Arq Bras Endocrinol Metabol. 2008;52(2):398-406. doi:10.1590/S000427302008000200028

14. Mustapa A, Justine M, Mohd Mustafah N, et al. Postural control and gait performance in the diabetic peripheral neuropathy: a systematic review. Biomed Res Int. 2016;2016:1-14. doi:10.1155/2016/9305025

15. Weintraub MI, Herrmann DN, Smith AG, et al. Pulsed electromagnetic fields to reduce diabetic neuropathic pain and stimulate neuronal repair: a randomized controlled trial. Arch Phys Med Rehabil. 2009;90(7):1102-1109. doi:10.1016/j.apmr.2009.01.019

16. Streckmann F, Zopf EM, Lehmann HC, et al. Exercise intervention studies in patients with peripheral neuropathy: a systematic review. Sports Med. 2014;44(9):1289-1304. doi:10.1007/s40279-014-0207-5

17. Amato Nesbit S, Sharma R, Waldfogel JM, et al. Non-pharmacologic treatments for symptoms of diabetic peripheral neuropathy: a systematic review. Curr Med Res Opin. 2019;35(1):15-25. doi:10.1080/ 03007995.2018.1497958

18. Zhang Y-J, Liu F-R, Ri H-S, Choi E-J, Choi YM, Yoon J-U. Effectiveness of acupuncture for treatment of diabetic peripheral neuropathy. Medicine. 2019;98(39). doi:10.1097/MD.0000000000017634

19. Waldfogel JM, Nesbit SA, Dy SM, et al. Pharmacotherapy for diabetic peripheral neuropathy pain and quality of life: a systematic review. Neurology. 2017;88(20):1958-1967. doi:10.1212/ WNL.0000000000003882

20. EL-REFAY BH, ALI OI. Efficacy of exercise rehabilitation program in improving gait of diabetic neuropathy patients. Assessment 2014;2013.

21. Allet L, Armand S, Aminian K, et al. An exercise intervention to improve diabetic patients' gait in a real-life environment. Gait Posture. 2010;32(2):185-190. doi:10.1016/j.gaitpost.2010.04.013

22. Suzuki K, Niitsu M, Kamo T, et al. Effect of exercise with rhythmic auditory stimulation on muscle coordination and gait stability in patients with diabetic peripheral neuropathy: a randomized controlled trial. Open $J$ Ther Rehabil. 2019;7(03):79. doi:10.4236/ ojtr.2019.73005

23. Cadore EL, Rodríguez-Mañas L, Sinclair A, et al. Effects of different exercise interventions on risk of falls, gait ability, and balance in physically frail older adults: a systematic review. Rejuvenation Res. 2013;16(2):105-114. doi:10.1089/rej.2012.1397

24. Allet L, Armand S, de Bie RA, et al. The gait and balance of patients with diabetes can be improved: a randomised controlled trial. Diabetologia. 2010;53(3):458-466. doi:10.1007/s00125-009-1592-4

25. Sartor CD, Hasue RH, Cacciari LP, et al. Effects of strengthening, stretching and functional training on foot function in patients with diabetic neuropathy: results of a randomized controlled trial. $B M C$ Musculoskelet Disord. 2014;15(1):137. doi:10.1186/1471-2474-15137

26. Shamseer L, Moher D, Clarke M, et al. Preferred reporting items for systematic review and meta-analysis protocols (PRISMA-P) 2015: elaboration and explanation. BMJ. 2015;349(jan02 1):g7647. doi:10.1136/bmj.g7647

27. Lee K, Lee S, Song C. Whole-body vibration training improves balance, muscle strength and glycosylated hemoglobin in elderly patients with diabetic neuropathy. Tohoku J Exp Med. 2013;231 (4):305-314. doi:10.1620/tjem.231.305

28. Sacco IDCN, Amadio AC. Influence of the diabetic neuropathy on the behavior of electromyographic and sensorial responses in treadmill gait. Clin Biomech. 2003;18(5):426-434. doi:10.1016/S02680033(03)00043-3
29. Salsabili H, Bahrpeyma F, Esteki A. The effects of Task-Oriented Motor Training on gait characteristics of patients with type 2 diabetes neuropathy. J Diabetes Metab Disord. 2015;15(1):14. doi:10.1186/ s40200-016-0236-8

30. Zange L. Effects of a combined strengthening, stretching, and functional training program versus usual care on gait biomechanics and foot function for diabetic neuropathy: a randomized controlled trial. $J$ Am Chiropractic Assoc. 2012;29-30.

31. Maher CG, Sherrington C, Herbert RD, et al. Reliability of the PEDro scale for rating quality of randomized controlled trials. Phys Ther. 2003;83(8):713-721. doi:10.1093/ptj/83.8.713

32. de Morton NA. The PEDro scale is a valid measure of the methodological quality of clinical trials: a demographic study. Aust $J$ Physiother. 2009;55(2):129-133. doi:10.1016/S0004-9514(09) 70043-1

33. Yamato TP, Maher C, Koes B, et al. The PEDro scale had acceptably high convergent validity, construct validity, and interrater reliability in evaluating methodological quality of pharmaceutical trials. J Clin Epidemiol. 2017;86:176-181. doi:10.1016/j.jclinepi.2017.03.002

34. Moseley AM, Elkins MR, Herbert RD, et al. Cochrane reviews used more rigorous methods than non-Cochrane reviews: survey of systematic reviews in physiotherapy. $J$ Clin Epidemiol. 2009;62 (10):1021-1030. doi:10.1016/j.jclinepi.2008.09.018

35. Guyatt GH, Oxman AD, Kunz R, et al. GRADE guidelines: 7. Rating the quality of evidence-inconsistency. J Clin Epidemiol. 2011;64 (12):1294-1302. doi:10.1016/j.jclinepi.2011.03.017

36. Melai T, Schaper NC, IJzerman TH, et al. Strength training affects lower extremity gait kinematics, not kinetics, in people with diabetic polyneuropathy. J Appl Biomech. 2014;30(2):221-230. doi:10.1123/ jab.2013-0186

37. Taveggia G, Villafañe JH, Vavassori F, et al. Multimodal treatment of distal sensorimotor polyneuropathy in diabetic patients: a randomized clinical trial. J Manipulative Physiol Ther. 2014;37(4):242-252. doi:10.1016/j.jmpt.2013.09.007

38. Mueller MJ, Tuttle LJ, LeMaster JW, et al. Weight-bearing versus nonweight-bearing exercise for persons with diabetes and peripheral neuropathy: a randomized controlled trial. Arch Phys Med Rehabil. 2013;94(5):829-838. doi:10.1016/j.apmr.2012.12.015

39. Grewal GS, Schwenk M, Lee-Eng J, et al. Sensor-based interactive balance training with visual joint movement feedback for improving postural stability in diabetics with peripheral neuropathy: a randomized controlled trial. Gerontology. 2015;61(6):567-574. doi: $10.1159 / 000371846$

40. Saleh MS, Rehab NI. Effect of ankle proprioceptive training on gait and risk of fall in patients with diabetic neuropathy: A randomized controlled trial. Int J Diabetes Res. 2019;2(1):40-45.

41. Saleh MSM, Rehab NI, Aly SMA. Effect of aquatic versus land motor dual task training on balance and gait of patients with chronic stroke: A randomized controlled trial. NeuroRehabilitation. 2019;44:1-8.

42. El-Sayed MS, Ali N, Ali ZE-S. Haemorheology in exercise and training. Sports Med. 2005;35(8):649-670. doi:10.2165/00007256200535080-00001

43. Higashi Y, Sasaki S, Kurisu S, et al. Regular aerobic exercise augments endothelium-dependent vascular relaxation in normotensive as well as hypertensive subjects: role of endothelium-derived nitric oxide. Circulation. 1999;100(11):1194-1202. doi:10.1161/01. CIR.100.11.1194

44. Gholami F, Nikookheslat S, Salekzamani Y, et al. Effect of aerobic training on nerve conduction in men with type 2 diabetes and peripheral neuropathy: A randomized controlled trial. Neurophys Clin. 2018;48(4):195-202. doi:10.1016/j.neucli.2018.03.001

45. Boulé NG, Haddad E, Kenny GP, et al. Effects of exercise on glycemic control and body mass in type 2 diabetes mellitus: a meta-analysis of controlled clinical trials. JAMA. 2001;286 (10):1218-1227. doi:10.1001/jama.286.10.1218 


\section{Publish your work in this journal}

Diabetes, Metabolic Syndrome and Obesity: Targets and Therapy is an international, peer-reviewed open-access journal committed to the rapid publication of the latest laboratory and clinical findings in the fields of diabetes, metabolic syndrome and obesity research. Original research, review, case reports, hypothesis formation, expert opinion and commentaries are all considered for publication. The manuscript management system is completely online and includes a very quick and fair peer-review system, which is all easy to use. Visit http://www.dovepress.com/testimonials.php to read real quotes from published authors.

Submit your manuscript here: https://www.dovepress.com/diabetes-metabolic-syndrome-and-obesity-targets-and-therapy-journal 